\title{
Comparison of uteroplacental glycosylation in the camel (Camelus dromedarius) and alpaca (Lama pacos)
}

\author{
C. J. P. Jones ${ }^{1}$, M. Abd-Elnaeim², E. Bevilacqua ${ }^{3}$, L. V. Oliveira ${ }^{3,4}$ \\ and R. Leiser ${ }^{5}$ \\ ${ }^{1}$ Academic Unit of Obstetrics and Gynaecology, School of Medicine, University of \\ Manchester, St Mary's Hospital, Whitworth Park, Manchester M13 OJH, UK; ${ }^{2}$ Department of \\ Anatomy and Histology, Faculty of Veterinary Medicine, Assiut University, Egypt; ${ }^{3}$ Institute of \\ Biomedical Sciences, University of São Paulo, Av. Prof. Lineu Prestes, 1524, São Paulo \\ 05508-900, Brazil; ${ }^{4}$ Faculty of Medicine Veterinary and Zootecnia, University of Antiplano, \\ Puno, Perú; and ${ }^{5}$ Institute for Veterinary Anatomy, Histology and Embryology, University of \\ Giessen, D-35392 Giessen, Germany
}

The recent birth of a camel-llama hybrid, after numerous failed attempts, has prompted an investigation into the glycosylation of apposing fetal and maternal tissues of pregnant camels and alpacas. This study was undertaken to determine whether interspecies differences in glycans are factors that may account in part for the difficulty in producing a viable hybrid. Specimens of camel placentae from day 60 to day 375 of gestation and alpaca placentae from day 22 to term (approximately 345 days) were fixed and embedded in resin, and sections were stained with a panel of 19 biotinylated lectins and an avidin-peroxidase revealing system. Several qualitative interspecies differences in tissue glycosylation were found, mainly in the trophoblast, and especially with respect to bi/tri-antennary bisected $\mathrm{N}$-glycan, fucosylated structures, $\beta$-galactosyl residues and sialyl termini. In the maternal uterine epithelium, differences were found mainly in bi/tri-antennary bisected complex $\mathrm{N}$-glycan and $\beta$-galactosyl residues, indicating that there is more conservation of glycosylation in maternal tissues compared with trophoblast. There were also many quantitative differences in the distribution of glycans. It is possible that a failure to effect the normal glycan-glycan complementation that occurs at the cell surface between maternal and fetal tissues during the implantation processes of apposition and adhesion may account in part for the difficulty in establishing a viable pregnancy between these two species.

\section{Introduction}

In recent years there has been much interest in the scientific and popular media following the birth of a camel-Ilama hybrid in Dubai (Gee, 1999; Roemer et al., 1999; Skidmore et al., 1999; Wright, 1999; Taylor, 2000). This was the first viable hybridization between the Old and New world camelids (Skidmore et al., 1999), and the result of 50 attempts to produce a cross between species that diverged 11 million years ago (Stanley et al., 1994). Jones et al. (2000) suggested that glycan-glycan interactions at the fetomaternal interface may play a role in successful implantation and subsequent maintenance of pregnancy, and that interspecies differences in glycosylation may be one mechanism for blocking inappropriate hybridization. In the present study, lectin histochemistry was used to compare the glycosylation of the adhering fetal and maternal tissues of the one-humped camel (Camelus dromedarius) and alpaca (Lama pacos), the latter species being able to interbreed with the Ilama (Lama guanicoe)

Email: carolyn.jones@man.ac.uk
(Gray, 1972). Such a comparison may help to determine whether there are significant differences between glycans of the camel and alpaca fetomaternal interfaces that may account in part for the difficulty encountered in producing a viable interspecies hybrid.

\section{Materials and Methods}

\section{Camels}

Nine uteri from pregnant camels were obtained from the Cairo (Egypt) abattoir. Placentae from fetuses at days 60, $70,90,145,170,210,265,350$ and 375 of gestation, calculated from curved crown-rump lengths of 4.5-115.0 $\mathrm{cm}$ (Elwishy et al., 1981), were perfusion fixed in 3\% (v/v) glutaraldehyde in $0.1 \mathrm{~mol}$ phosphate buffer $\mathrm{I}^{-1}(\mathrm{pH} 7.3)$. The placentae were then immersion fixed for $2 \mathrm{~h}$ and washed in buffer. Full depth slices of placental tissue were dehydrated in an ascending alcohol series, treated with propylene oxide and infiltrated with Taab epoxy resin (Taab Laboratories Equipment Ltd, Aldermaston), and were embedded in flat-bottomed capsules and polymerized at $60^{\circ} \mathrm{C}$ for $72 \mathrm{~h}$. 


\section{Alpacas}

Breeding and pregnancy determination. During the breeding season, for a period of $2 \mathrm{~h}$ (from 06:00 $\mathrm{h}$ to 08:00 h), a total of 20 pairs was isolated from the group and left in pairs in a fenced area of $10 \mathrm{~m} \times 5 \mathrm{~m}$. The animals were observed and after coitus they were marked properly. The day of coitus was considered as day 1 of pregnancy. Fifteen days later, pregnancy was confirmed by nonreceptive behaviour in the presence of males, uterine rectal palpation and ultrasonography. In total, seven animals were selected for this study at days 22, 45, 150, 264, 283, 296 and 347 of pregnancy. All procedures were performed in accordance with the ethical principles for animal research adopted by the Brazilian College of Animal Experimentation and the experimental protocol was approved by the Biomedical Sciences Institute, University of São Paulo Ethical Committee for Animal Research (no. 027/98).

Collection and processing of tissue from the embryonicmaternal interface. Laparotomies were performed on all animals under general anaesthesia using sodium pentobarbital (30 $\mathrm{mg} \mathrm{kg}^{-1}$ administered i.v.) and cervical denervation. The reproductive organs were exposed through a mid-ventral incision of about $10 \mathrm{~cm}$ in length and the uteri and ovaries were removed. The ovaries were analysed for counting of the corpora lutea and the uteri were cut into small fragments of approximately $10 \mathrm{~mm} \times 3$ $\mathrm{mm} \times 2 \mathrm{~mm}$ for light microscopic studies and $2 \mathrm{~mm} \times 3$ $\mathrm{mm} \times 2 \mathrm{~mm}$ for ultrastructural analysis. These fragments were fixed rapidly by immersion in $2.5 \%(\mathrm{v} / \mathrm{v})$ glutaraldehyde in 0.1 mol phosphate buffer $\mathrm{I}^{-1}, \mathrm{pH} 7.4$. For lectin histochemistry, tissues were washed in PBS, dehydrated in a graded ethanol series and embedded in Spurr resin (medium grade; Electron Microscopic Science Co., St Louis, MO). The camel (day 60) and alpaca (day 150) tissues that had been post-fixed in $1 \%(\mathrm{w} / \mathrm{v})$ osmium tetroxide and processed for electron microscopy were also sectioned and stained with uranyl acetate and lead citrate before examination in a Zeiss EM109 or Philips EM301 to determine the morphology of secretory granules at the fetomaternal interface.

\section{Lectin histochemistry}

Suitable areas from non-osmicated blocks of both species were identified on $0.5 \mu \mathrm{m}$ thick sections stained with $1 \%$ $(\mathrm{w} / \mathrm{v})$ toluidine blue in $1 \%(\mathrm{w} / \mathrm{v})$ aqueous sodium tetraborate. Sections $(0.75 \mu \mathrm{m}$ thickness) were cut for lectin histochemistry, mounted on 3-aminopropyltriethoxysilane (APES)-coated slides (Maddox and Jenkins, 1987) and stained with a panel of 19 biotinylated lectins and an avidin-peroxidase revealing system as described by Jones et al. (2000). Resin was removed with saturated sodium ethoxide diluted 1:1 with absolute ethanol for $15 \mathrm{~min}$ and, after washing in ethanol followed by distilled water, endogenous peroxidase was blocked with 10\% (v/v) hydrogen peroxide (100 volumes; $\mathrm{BDH}$, Poole) before exposure to $0.03 \%(w / v)$ trypsin (Type II-S; Sigma, Poole) in 0.05 mol Tris-buffered saline (TBS) $\mathrm{I}^{-1}, \mathrm{pH} 7.6$, for 4 min at $37^{\circ} \mathrm{C}$. After washing, the sections were incubated with $10 \mu \mathrm{g}$ biotinylated lectin $\mathrm{ml}^{-1}$ (Sigma; SNA from Boehringer Mannheim, Lewes; MAA, DSA and STA from Vector Laboratories, Peterborough; LFA from EY Laboratories, San Mateo, CA; see Table 1 for major sugar specificities) in $0.05 \mathrm{~mol} \mathrm{TBS}^{-1}$ containing $1 \mathrm{mmol}$ calcium chloride $\mathrm{I}^{-1}$ for $1 \mathrm{~h}$ at $37^{\circ} \mathrm{C}$, washed in the same buffer, then treated with 5

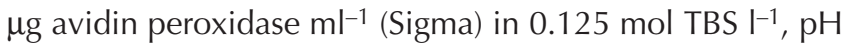
7.6, with $0.347 \mathrm{~mol}$ sodium chloride $\mathrm{I}^{-1}$ for $1 \mathrm{~h}$ at $37^{\circ} \mathrm{C}$ (Jones et al., 1987). Sections were washed and sites of lectin binding were revealed using $0.05 \%(\mathrm{w} / \mathrm{v})$ diaminobenzidine tetrahydrochloride dihydrate (Aldrich Chemical Co., Gillingham) in 0.05 mol TBS I-1, $\mathrm{pH} 7.6$, and $0.015 \%(\mathrm{v} / \mathrm{v})$ hydrogen peroxide (100 volumes) for $5 \mathrm{~min}$ at $18.0 \pm 0.5^{\circ} \mathrm{C}$. The sections were rinsed, air-dried and mounted in neutral synthetic mounting medium (BDH).

Controls were performed as described by Jones et al. (1995). Sections were assessed using a semi-quantitative ranking system of analysis in which staining intensity was allocated a grade from 0 (negative) to 4 (intense staining), and granule density was scored from sparse $(+/-)$ to numerous $(++++)$.

\section{Results}

\section{Histological structure of the fetomaternal interface}

Both species of camelid had an epitheliochorial type of placentation, with close interdigitation of the microvillous surface of the fetal trophoblast with that of the maternal uterine epithelium. Initially, this interaction created a more or less flat or slightly undulating interface (Fig. 1a,b), but at progressive stages of gestation the profile changed so that the trophoblast produced blunt placental outgrowths and the maternal epithelium had equivalent crypts. In the camel, these remained relatively simple until term, but in the alpaca the villous outgrowths were more complex. Occasional trophoblast giant cells were seen in some of the camel specimens (days 60, 90, 170, 210, 350 and 375 of gestation), with many nuclear profiles, and these cells were more prevalent in alpacas, with several giant cells often visible in a single section (Fig. 1h). Blood vessels were found underlying the uterine epithelial cells and also indenting the trophoblast. The developmental changes that occur during gestation in camel $(\mathrm{a}, \mathrm{c}, \mathrm{e}, \mathrm{g})$ and alpaca $(\mathrm{b}, \mathrm{d}, \mathrm{f}, \mathrm{h})$ are shown (Fig. 1).

\section{Ultrastructure of granules}

At the ultrastructural level, camel maternal epithelium contained a mainly supranuclear population of round secretory droplets (Fig. 2a), whereas the trophoblast (Fig. 2b) contained a range of different-sized granules, some of which were very pleomorphic. Many mitochondria, welldeveloped Golgi bodies and large numbers of cisternae of rough endoplasmic reticulum were also present to a 
Table 1. Lectins used and their major specificities

\begin{tabular}{|c|c|c|c|}
\hline Acronym & Source & Major specificity & Reference \\
\hline PSA & $\begin{array}{l}\text { Pisum sativum } \\
\text { Garden pea }\end{array}$ & $\begin{array}{l}\alpha \text {-D-mannose in non-bisected bi/tri-antennary, } \\
\text { complex } N \text {-linked sequences }\end{array}$ & $\begin{array}{l}\text { Trowbridge, } 1974 \\
\text { Debray et al., } 1981\end{array}$ \\
\hline e-PHA & $\begin{array}{l}\text { Phaseolus vulgaris } \\
\text { (erythroagglutinin) } \\
\text { Kidney bean }\end{array}$ & $\begin{array}{l}\text { Bi/tri-antennary bisected complex } N \text {-linked } \\
\text { sequences }\end{array}$ & $\begin{array}{l}\text { Cummings and Kornfeld, } 1982 \\
\text { Yamashita et al., } 1983\end{array}$ \\
\hline I-PHA & $\begin{array}{l}\text { Phaseolus vulgaris } \\
\text { (leukoagglutinin) } \\
\text { Kidney bean }\end{array}$ & $\begin{array}{l}\text { Tri/tetra-antennary, non-bisected complex } \\
N \text {-linked sequences }\end{array}$ & $\begin{array}{l}\text { Hämmarstrom et al., } 1982 \\
\text { Green and Baenziger, } 1987\end{array}$ \\
\hline DSA & $\begin{array}{l}\text { Datura stramonium } \\
\text { Jimson weed }\end{array}$ & $\beta 1,4 \mathrm{GlcNAc}, N$-acetyl lactosamine $>$ chitotriose & $\begin{array}{l}\text { Crowley et al., } 1984 \\
\text { Yamashita et al., } 1987\end{array}$ \\
\hline STA & $\begin{array}{l}\text { Solanum tuberosum } \\
\text { Potato }\end{array}$ & $\beta 1,4 \mathrm{Glc} N A c$ oligomers & $\begin{array}{l}\text { Allen and Neuberger, } 1973 \\
\text { Debray et al., } 1981\end{array}$ \\
\hline LEA & $\begin{array}{l}\text { Lycopersicon esculentum } \\
\text { Tomato }\end{array}$ & $\beta 1,4 \mathrm{Glc} N A c$ oligomers & Nachbar et al., 1980 \\
\hline ECA & $\begin{array}{l}\text { Erythrina cristagalli } \\
\text { Coral tree }\end{array}$ & Gal $\beta 1,4 \mathrm{Glc} N A c \beta 1-$ & $\begin{array}{l}\text { Iglesias et al., } 1982 \\
\text { De Boeck et al., } 1984\end{array}$ \\
\hline $\mathrm{AHA}$ & $\begin{array}{l}\text { Arachis hypogaea } \\
\text { Peanut }\end{array}$ & Gal $\beta 1,3$ Gal $N A c \beta 1$ - > Gal $\beta 1,4$ Glc $N A c \beta 1-$ & $\begin{array}{l}\text { Lotan and Sharon, } 1978 \\
\text { Sueyoshi et al., } 1988\end{array}$ \\
\hline MPA & $\begin{array}{l}\text { Maclura pomifera } \\
\text { Osage orange }\end{array}$ & Gal $\beta 1,3$ GalNAc $\alpha 1$ - > GalNAc $\alpha 1$ - & Sarkar et al., 1981 \\
\hline HPA & $\begin{array}{l}\text { Helix pomatia } \\
\text { Roman snail }\end{array}$ & Terminal GalNAc $\alpha 1$ - & $\begin{array}{l}\text { Hammarström et al., } 1977 \\
\text { Torres et al., } 1988\end{array}$ \\
\hline SBA & $\begin{array}{l}\text { Glycine max } \\
\text { Soybean }\end{array}$ & Terminal GalNAc $\alpha 1->$ Gal $\alpha 1$ & $\begin{array}{l}\text { Pereira et al., } 1974 \\
\text { Bhattacharyya et al., } 1988\end{array}$ \\
\hline WFA & $\begin{array}{l}\text { Wisteria floribunda } \\
\text { Wisteria }\end{array}$ & GalNAc $\alpha 1,6$ Gal $\beta 1$ - > GalNAc $\alpha 1,3$ Gal $\beta 1$ - & $\begin{array}{l}\text { Sugii and Kabat, } 1980 \\
\text { Baker et al., } 1983\end{array}$ \\
\hline DBA & $\begin{array}{l}\text { Dolichos biflorus } \\
\text { Horse gram }\end{array}$ & GalNAc $\alpha 1,3($ Lfuc $\alpha 1,2)$ Gal- $\beta 1,3 / 4$ Glc $N A c \beta 1-$ & $\begin{array}{l}\text { Etzler and Kabat, } 1970 \\
\text { Baker et al., } 1983\end{array}$ \\
\hline UEA-1 & $\begin{array}{l}\text { Ulex europaeus- } 1 \\
\text { Gorse }\end{array}$ & $\mathrm{H}$ type 2 antigen ( $\alpha \mathrm{L}-\mathrm{Fuc}(1,2)$ Gal $\beta 1,4 \mathrm{Gl} N \mathrm{CAc} \beta 1-)$ and $\mathrm{Le}^{y}$ & $\begin{array}{l}\text { Hindsgaul et al., } 1985 \\
\text { Baldus et al., } 1996\end{array}$ \\
\hline LTA & $\begin{array}{l}\text { Tetragonolobus purpureus } \\
\text { Lotus }\end{array}$ & 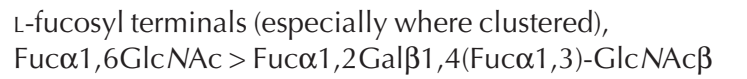 & $\begin{array}{l}\text { Pereira and Kabat, } 1974 \\
\text { Debray et al., } 1981\end{array}$ \\
\hline SNA & $\begin{array}{l}\text { Sambucus nigra } \\
\text { Elderberry bark }\end{array}$ & NeuNAc $2,6 \mathrm{Gal} / \mathrm{GalNAc-}$ & Shibuya et al., 1987 \\
\hline MAA & Maackia amurensis & NeuNAc $\alpha 2,3$ Gal $\beta 1$ - & $\begin{array}{l}\text { Wang and Cummings, } 1988 \\
\text { Knibbs et al., } 1991\end{array}$ \\
\hline LFA & $\begin{array}{l}\text { Limax flavus } \\
\text { Yellow slug }\end{array}$ & Certain sialyl termini & $\begin{array}{l}\text { Miller et al., } 1982 \\
\text { Knibbs et al., } 1993\end{array}$ \\
\hline WGA & $\begin{array}{l}\text { Triticum vulgaris } \\
\text { Wheatgerm }\end{array}$ & $\begin{array}{l}\text { Di- } N \text {-acetyl chitobiose, } N \text {-acetyl lactosamine } \\
\text { (especially if clustered) and some sialyl residues }\end{array}$ & Gallagher et al., 1985 \\
\hline
\end{tabular}

significant degree, reflecting cellular secretory activity. The alpaca placenta was broadly similar (Fig. 2c-e) to that of the camel except that, at the stage examined (day 150), the granules in the maternal epithelium were very sparse (Fig. 2c) and in the trophoblast the pleomorphic granules were situated mainly in the basal part of the cell (Fig. 2d), whereas small electron-lucent vesicles were found apically. Examination of the fetomaternal interface demonstrated the intimate association between the two tissues (Fig. 2e) and the presence of cytoplasmic filaments, which indicate a possible contractile function of the microvilli. In places, vesicles or dilatations of the intercellular space were found in association with the basal areas of the microvilli, especially in the trophoblast.

\section{Lectin histochemistry}

The binding properties of the placentae are summarized (Table 2). Not much variation in glycosylation was observed in either camel or alpaca during the course of pregnancy and, hence, two time points have been chosen to illustrate early and late gestation: days 70 and 350 in camel, and days 45 and 347 in alpaca. Both species had areolae associated with the trophoblast layer, but these have not been included in the analysis.

\section{Maternal uterine epithelium}

Camel. There was an increase with time in the binding of LTA to granules (Fig. 3a), which was significant only from 

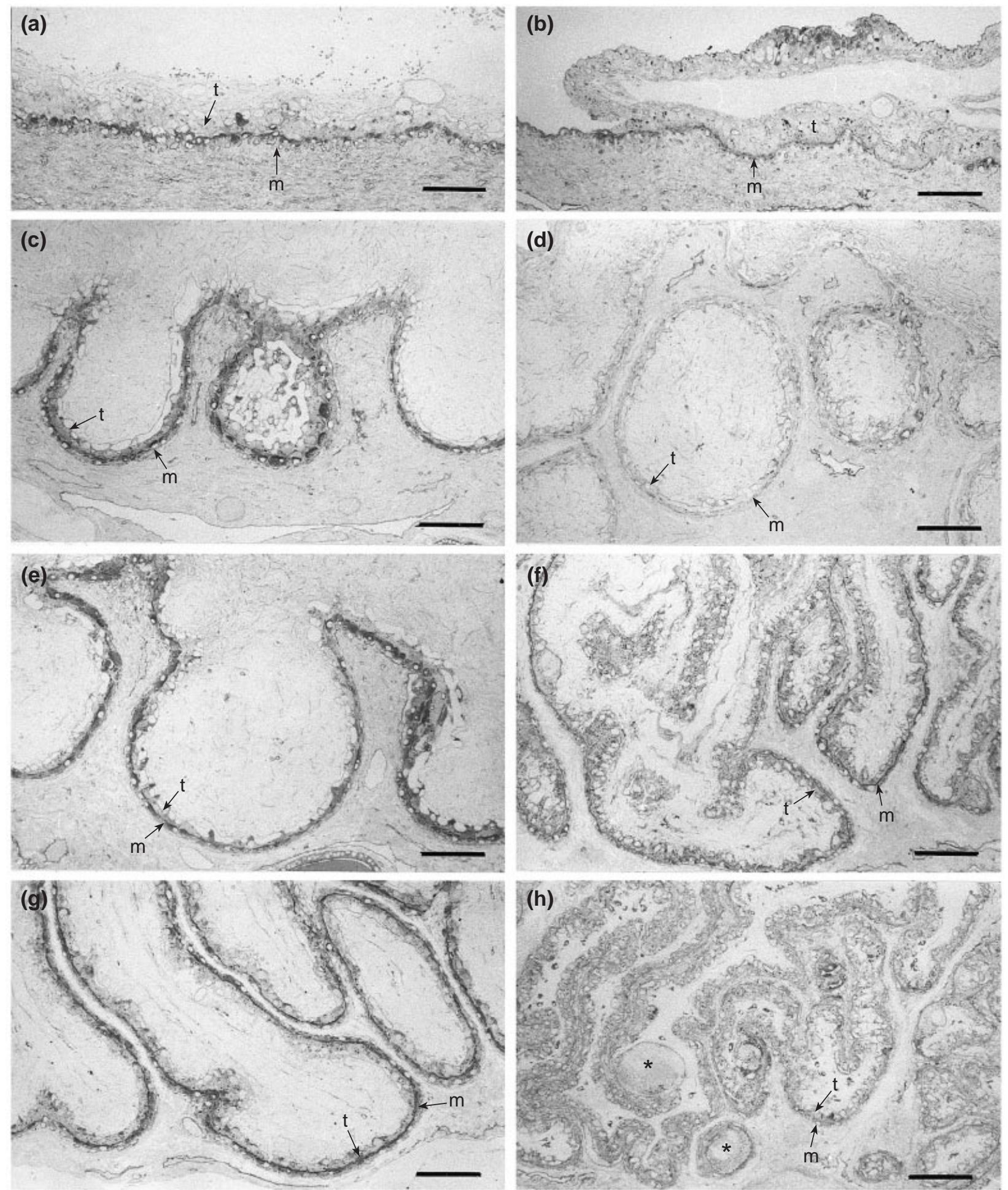

Fig. 1. (a,c,e,g) Development of the camel placenta. Low power views at days (a) 70, (c) 170, (e) 210 and (g) 375 of gestation stained with the lectin from Lycopersicon esculentum (LEA) to show blunt villous development. Trophoblast ( $\mathrm{t}$ ) and maternal epithelium (m) can be seen. (b,d,f,h) Development of the alpaca placenta. Low power views at days (b) 45, (d) 150, (f) 283 and (h) 347 of gestation stained with LEA. The villi show a more complex branching structure than those of the camel. Two giant cells $(*)$ are visible in (h). Scale bars represent $50 \mu \mathrm{m}$. 

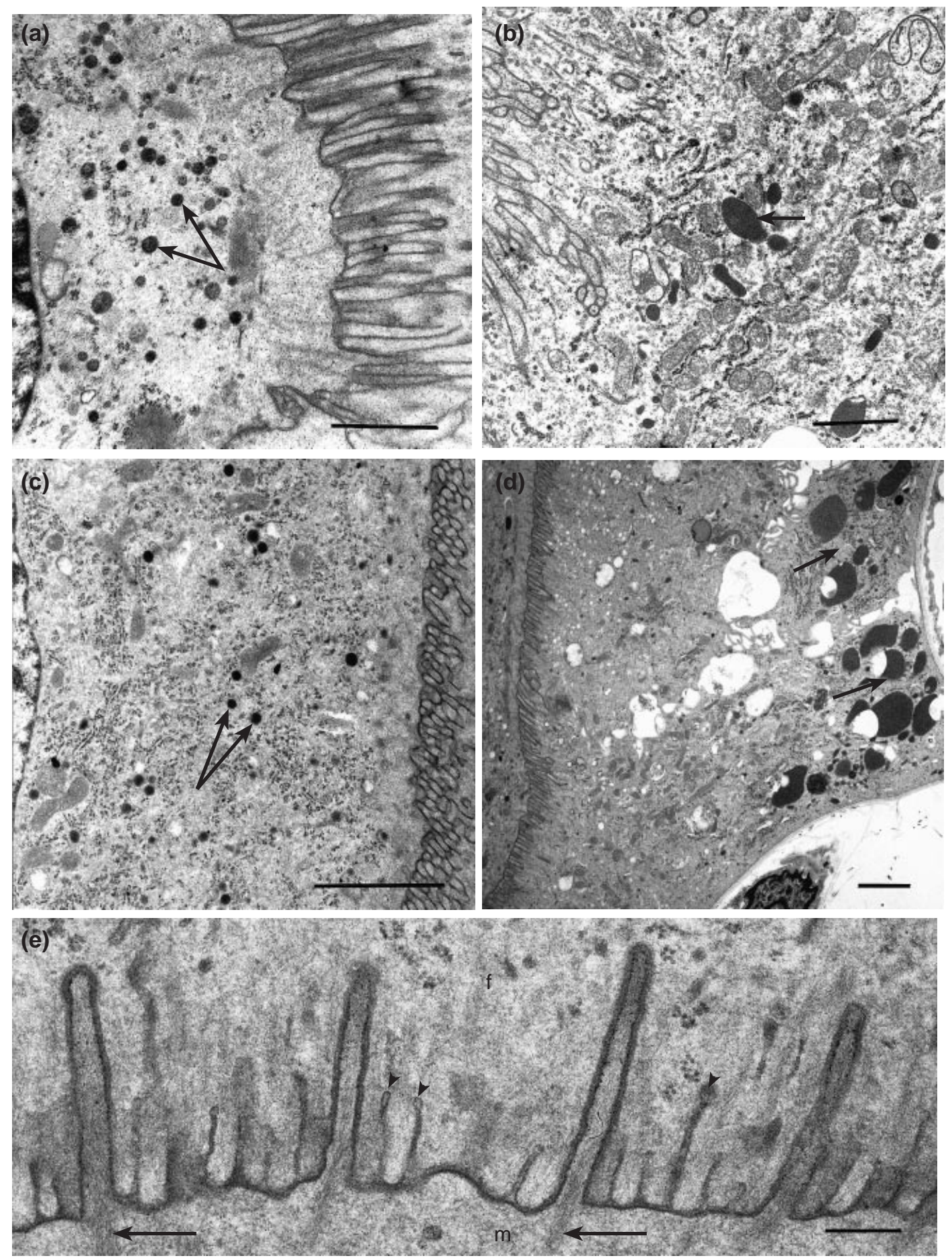

Fig. 2. (a,b) Ultrastructure of the camel fetomaternal interface at day 60 of gestation. (a) Maternal uterine epithelium showing round apical secretory droplets (arrows). (b) Trophoblast: inclusions (arrow) are more pleomorphic and irregular in size. (c-e) Ultrastructure of the alpaca fetomaternal interface at day 150 of gestation. (c) Maternal epithelium showing sparse, small, electron-dense secretory droplets (arrows). (d) Trophoblast: large, pleomorphic inclusions (arrows) are found towards the basal aspect of the cell. (e) Interdigitating microvillous membrane showing the intimate connection between the fetal $(f)$ and maternal $(m)$ surfaces. The maternal microvilli appear to be more sparse than those of the trophoblast and are longer than their fetal equivalents, with longitudinal cytoplasmic filaments running within them (arrows). The microvilli of the trophoblast tend to lie against the surface of the maternal epithelium and may have small vesicles or dilatations of the intercellular space associated with the basal areas (arrowheads). Scale bars represent (a,b) $1 \mu \mathrm{m},(\mathrm{c}, \mathrm{d}) 2 \mu \mathrm{m}$ and (e) $250 \mathrm{~nm}$. 
Table 2. Lectin binding properties of camel and alpaca trophoblast and uterine epithelium at early and late gestation

\begin{tabular}{|c|c|c|c|c|c|c|c|c|}
\hline \multirow[b]{3}{*}{ Lectin } & \multicolumn{4}{|c|}{ Uterine epithelium } & \multicolumn{4}{|c|}{ Trophoblast } \\
\hline & \multicolumn{2}{|c|}{ Early gestation } & \multicolumn{2}{|c|}{ Late gestation } & \multicolumn{2}{|c|}{ Early gestation } & \multicolumn{2}{|c|}{ Late gestation } \\
\hline & $\begin{array}{c}\text { Camel } \\
\text { (day } 70)\end{array}$ & $\begin{array}{l}\text { Alpaca } \\
\text { (day 45) }\end{array}$ & $\begin{array}{c}\text { Camel } \\
\text { (day 350) }\end{array}$ & $\begin{array}{l}\text { Alpaca } \\
\text { (day 347) }\end{array}$ & $\begin{array}{l}\text { Camel } \\
\text { (day 70) }\end{array}$ & $\begin{array}{l}\text { Alpaca } \\
\text { (day 45) }\end{array}$ & $\begin{array}{c}\text { Camel } \\
\text { (day 350) }\end{array}$ & $\begin{array}{c}\text { Alpaca } \\
\text { (day 347) }\end{array}$ \\
\hline PSA & $3++++$ & $3-4+$ & $3++$ & $4+/-$ & $3++$ & $3-4++$ & $2+++$ & $3-4++$ \\
\hline $\mathrm{E}-\mathrm{PHA}$ & $2-3+++$ & $2-3++$ & $2 * a$ & $0^{\mathrm{a}}$ & $2^{*}$ & $4+/-$ & $2 * a$ & $0^{\mathrm{a}}$ \\
\hline L-PHA & 0 & $1+/-$ & 0 & 0 & 0 & 0 & 0 & 0 \\
\hline DSA & $3+++$ & $3-4++++$ & $2-3++$ & $3-4+++$ & $3++$ & $3-4+++$ & $3-4++$ & $3-4+++$ \\
\hline STA & $3-4+++$ & $2-3+++$ & $3++$ & $3-4+++$ & $2-4++$ & $3-4+++$ & $3-4++$ & $3-4+++$ \\
\hline LEA & $3-4+++$ & $3-4+++$ & $3+++$ & $3-4+++$ & $2-4+$ & $2-4++$ & $3-4++$ & $3-4+++$ \\
\hline ECA & $3+++$ & $3+$ & $3++$ & $3+$ & $4+/-$ & $2-3+/-$ & $2-4+$ & $1+$ \\
\hline $\mathrm{AHA}$ & $3+$ & $3+/-$ & $4++^{a}$ & $0^{\mathrm{a}}$ & $0^{\mathrm{a}}$ & $3-4++^{a}$ & $3+/-$ & $2-3++$ \\
\hline MPA & $3+++$ & $4++$ & $2++$ & $2+/-$ & $3+++$ & $2-4++$ & $3++++$ & $3+++$ \\
\hline $\mathrm{HPA}$ & $2-3+$ & $3-4++$ & $3+$ & $4+$ & $3-4++$ & $2-4++$ & $3-4++$ & $3-4+++$ \\
\hline SBA & $3+++$ & $3++$ & $4++$ & $3++$ & $4+/-$ & $3+/-$ & $3++$ & $2-3++$ \\
\hline WFA & $4+++$ & $3-4+++$ & $4++$ & $4++$ & $4+$ & $3-4++$ & $4+++$ & $3-4++$ \\
\hline DBA & $3+$ & $1-2+++$ & 0 & 0 & $0^{\mathrm{a}}$ & $2-3++^{\mathrm{a}}$ & $0^{\mathrm{a}}$ & $1-2++^{a}$ \\
\hline UEA-1 & $3++$ & $3+$ & $3++$ & $4++$ & 0 & $3+/-$ & $4+/-$ & $4+/-$ \\
\hline LTA & $1+$ & 0 & $3++$ & $4+$ & $2-3++$ & $2-3++$ & $3++$ & $2-3+++$ \\
\hline SNA & 0 & $2+$ & 0 & 0 & 0 & $3+1-$ & 0 & 0 \\
\hline MAA & 0 & $3+$ & 0 & $2+/-$ & $0^{\mathrm{a}}$ & $2-4+++^{a}$ & $0^{\mathrm{a}}$ & $2-3+++^{a}$ \\
\hline LFA & 0 & 0 & 0 & 0 & 0 & 0 & 0 & 0 \\
\hline WGA & $4+++$ & $4++$ & $3++$ & $3+$ & $4+$ & $2-4++$ & $2-4+++$ & $3-4++$ \\
\hline
\end{tabular}

Staining: 0 : negative; 1 : weak; 2 : moderate; 3 : strong; 4 : intense.

Granule density: +/- : occasional; +: sparse; ++: few; +++: many; ++++: numerous.

*The staining with e-PHA was uniform and not granular in these cases.

andicates significant differences between the two species at that stage of gestation.

day 145 of gestation, whereas binding of SBA decreased from about day 265, and binding of WFA (Fig. 3C) and WGA decreased from day 350. There was no binding of I-PHA, SNA, MAA or LFA at any stage, whereas DBA stained occasional granules up to day 110 of gestation and was then negative until day 375, when weak staining was again observed. Binding of several lectins, namely PSA (Fig. 3e), ePHA (Fig. 4a), UEA-1, MPA, AHA (Fig. 4c,e), ECA (Fig. 5a), LEA (Fig. 5C), DSA, STA (Fig. 5e) and HPA was fairly consistent throughout gestation. The maternal epithelium became somewhat flattened during the course of pregnancy.

Alpaca. There was a loss in the binding of e-PHA (Fig. 4b), I-PHA and SNA after day 45 of gestation, at which point LTA staining was observed (Fig. 3b). AHA bound to a scarce subpopulation of granules up to day 150 only (Fig. 4 d,f) and DBA bound weakly, or not at all, to a subpopulation of granules. LFA did not bind in this tissue and many lectins, namely PSA (Fig. 3f), LTA (Fig. 3b), WFA (Fig. 3d), UEA-1, MPA and ECA (Fig 5b), HPA, SNA, MAA and WGA stained a subpopulation of granules only. More widespread staining was observed with SBA, DSA, LEA and STA (Fig. 5d,f).

\section{Trophoblast}

Camel. There was no binding of I-PHA, DBA (except for a very occasional granule at day 170), SNA, MAA or LFA.
Many granules stained with PSA, MPA, DSA and STA (Figs $3 \mathrm{e}$ and $5 \mathrm{e}$ ), whereas subpopulations bound LEA (Fig. 5c) and HPA in early pregnancy. There was diffuse cytoplasmic staining with e-PHA (Fig. 4a), with some granular staining between day 90 and day 265 of gestation, and an increase in the binding of LTA, SBA, WFA and WGA to granules was observed over the course of gestation (Fig. 3a,c). Occasional granules were stained with UEA-1 at days 145 , 170 and 350 of gestation, and the density of granules within cells also varied with $\mathrm{AHA}$; few granules were present at day 60 and from day 145 to day 375 (Fig. 4e). ECA binding was absent at day 60, but occasional granules bound thereafter (Fig. 5a). The giant cells were sparse and were not observed in every specimen; in general they stained in a similar way to the rest of the trophoblast. MPA bound less strongly. There was a tendency for the staining of giant cells, as with the trophoblast in general, to be somewhat polarized, with the most intense stain being near the microvillous border (Fig. 5e); this often led to a variegated appearance to the trophoblast in sections.

Alpaca. There was no binding of I-PHA or LFA, and only very occasional granules stained with SNA at days 22 and 45 of gestation. Granules bound LTA (Fig. 3b), WFA (Fig. 3d), PSA (Fig. 3f), MPA, AHA (Fig. 4d,f), DSA, LEA (Fig. 5d), STA (Fig. 5f), HPA, MAA and WGA, and pleomorphism was 

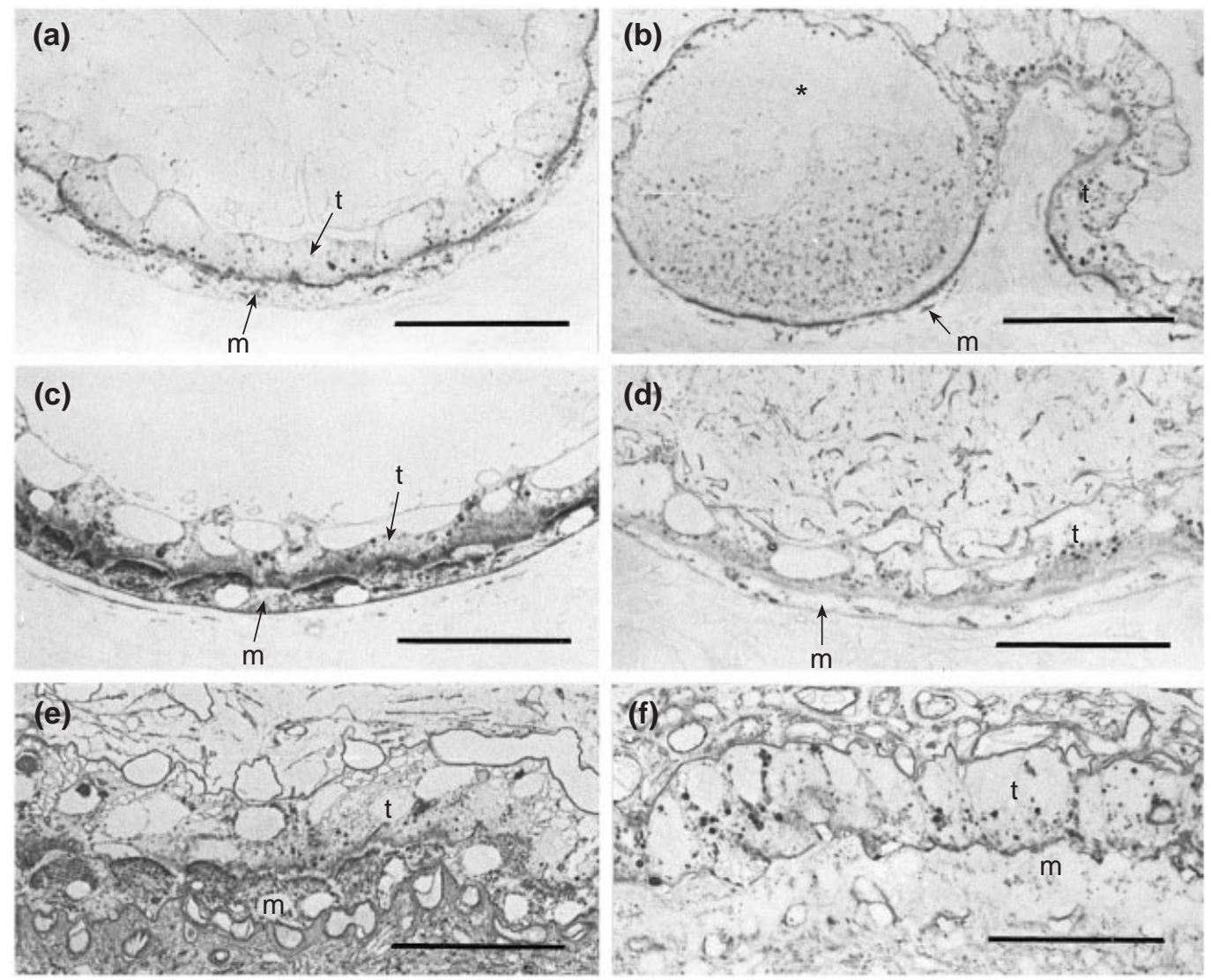

Fig. 3. (a,b) Tetragonalobus purpureus agglutinin (LTA). (a) At day 375 of gestation, sparse granules are observed in both the maternal epithelium $(\mathrm{m})$ and the trophoblast $(\mathrm{t})$ of camel, with a more strongly staining interdigitating microvillous membrane. (b) In alpaca at day 347 of gestation, the trophoblast shows moderate staining with only occasional granules in the maternal epithelium (arrow). The giant cell $(*)$ shows a gradation in binding, which is concentrated near the microvillous surface. (c,d) Wisteria floribunda agglutinin (WFA). (c) At day 170 of gestation there is strong binding of this lectin to both maternal epithelium and trophoblast of camel at this stage of pregnancy. (d) At day 150 of gestation there is less binding of WFA to both maternal epithelium and trophoblast of alpaca. (e,f) Pisum sativum agglutinin (PSA). (e) At day 70 of gestation the maternal epithelium has many lectin-binding granules in camel, whereas in the trophoblast, granules are more pleomorphic and sparse. (f) At day 45 of gestation there are only very occasional PSApositive granules in the maternal epithelium in alpaca, but a variety of different granules, some of which stain strongly, in the trophoblast. Scale bars represent $50 \mu \mathrm{m}$.

often apparent, some granules attaining considerable size, especially in the early stages of gestation (Figs 3f, 4d and $5 \mathrm{~d})$. There was a loss of binding of e-PHA at day 264 of gestation (Fig. 4b) and of UEA-1 at day 283 of gestation, although binding had been very sparse in the latter case. DBA staining became weaker over the course of pregnancy and ECA bound to a subpopulation of sparse granules only (Fig. 5b), with hardly any staining at day 296 and term. There was a slight increase in the number of granules binding SBA from day 264. In general, the giant cells showed the same binding characteristics as the rest of the trophoblast (Fig. 5f), although they sometimes appeared slightly paler with more homogeneous granulation (Fig. $4 \mathrm{f}$ ). There was often a clear zonation within the cell: most staining was observed in an area underneath the microvillous membrane, whereas the rest of the cell was stained less intensely (Fig. 3b). However, at term, the staining was generally stronger than in the rest of the trophoblast; this was particularly marked with PSA, MPA, SBA, WFA, HPA and WGA.

\section{Interdigitating microvillous membrane}

In general, there was no lectin binding to the membrane when both tissues were unstained. An exception was DBA binding to the alpaca microvillous membrane, which sometimes stained intensely even though the two tissue layers had little reactivity, indicating the possibility of glycosyl transferase activity at the cell surface. However, usually the membrane was stained only by lectins where 

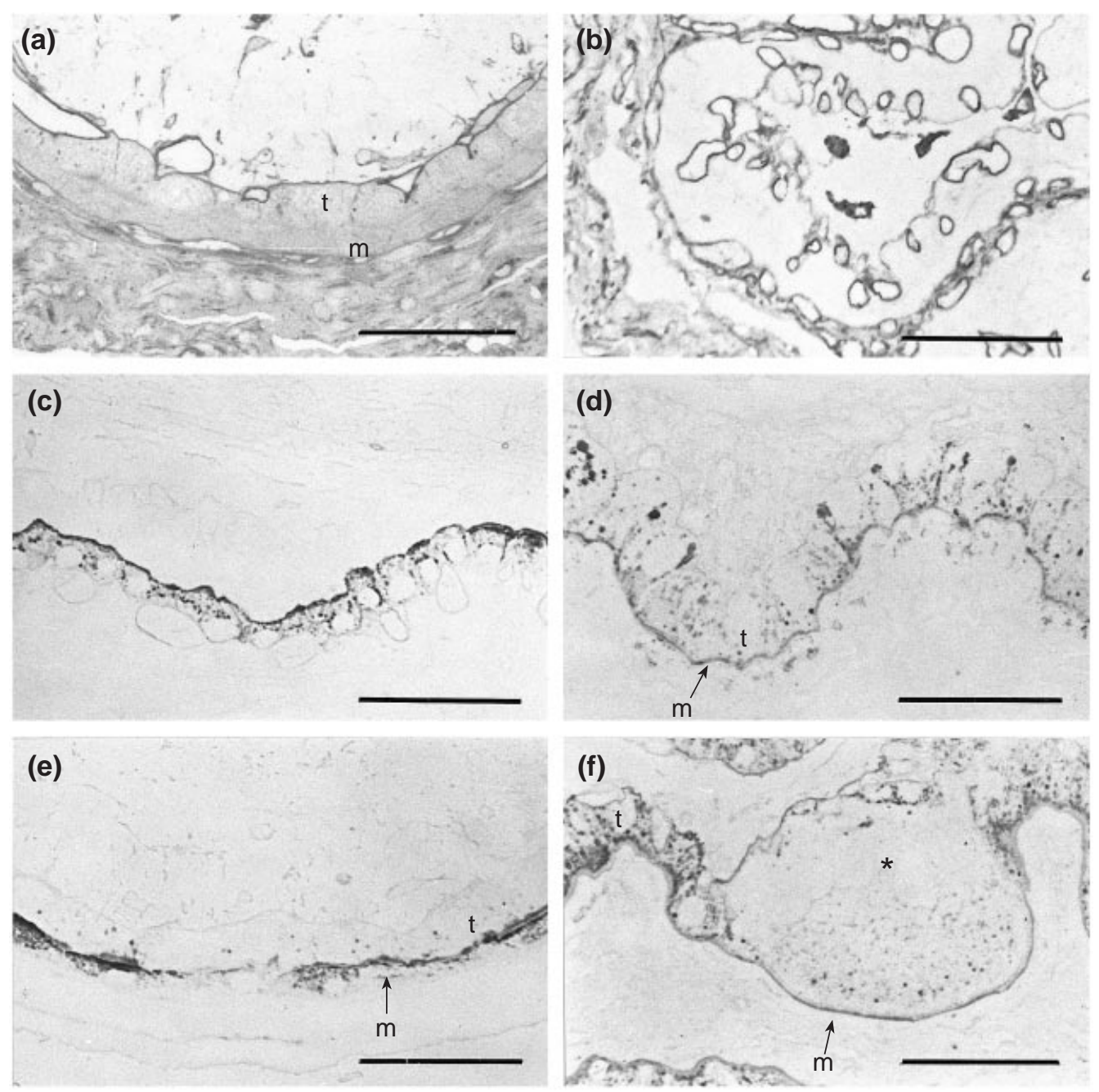

Fig. 4. (a,b) Phaseolus vularis erythroagglutinin (e-PHA). (a) Staining with e-PHA is very diffuse in the camel trophoblast $(\mathrm{t})$ and maternal epithelium $(\mathrm{m})$ at day 375 of gestation. (b) At day 347 of gestation in alpaca, there is no binding of e-PHA, although blood capillaries stain strongly. (c,d) Arachis hypogaea agglutinin (AHA). (c) At day 90 of gestation in camel, AHA shows moderate binding to granules in the maternal epithelium only. (d) At day 45 of gestation in alpaca, there is some binding to the maternal epithelium and many different granules are stained in the trophoblast. (e,f) Arachis hypogaea agglutinin (AHA). (e) At day 375 of gestation in camel there is still binding of AHA to the maternal epithelium and occasional positive granules in the trophoblast. ( $\mathrm{f}$ ) At day 347 of gestation there is no binding to the maternal epithelium but moderate staining of the trophoblast in alpaca. A giant cell (*) appears slightly paler than the rest of the trophoblast. Scale bars represent $50 \mu \mathrm{m}$.

one of the two cell layers (maternal or fetal) contained lectin-positive granules, which were probably secreted on the microvillous surface. The vesicles or dilatations associated with the basal areas of the trophoblastic microvilli may be involved in the secretion or uptake of material at this interface. The staining properties of the interdigitating microvillous membrane depended to some extent on the closeness of the attachment between the two tissues. It became clear from examination of free surfaces (where they had detached from each other during specimen preparation) that some steric hindrance often occurred in the intact tissue, which reduced the binding of the lectin. This resulted in much weaker staining than when the same surfaces were free.

\section{Controls}

Substitution of buffer for the lectin resulted in the absence of staining, whereas incubation of the lectin in the presence of its inhibitory sugar reduced or eliminated the 

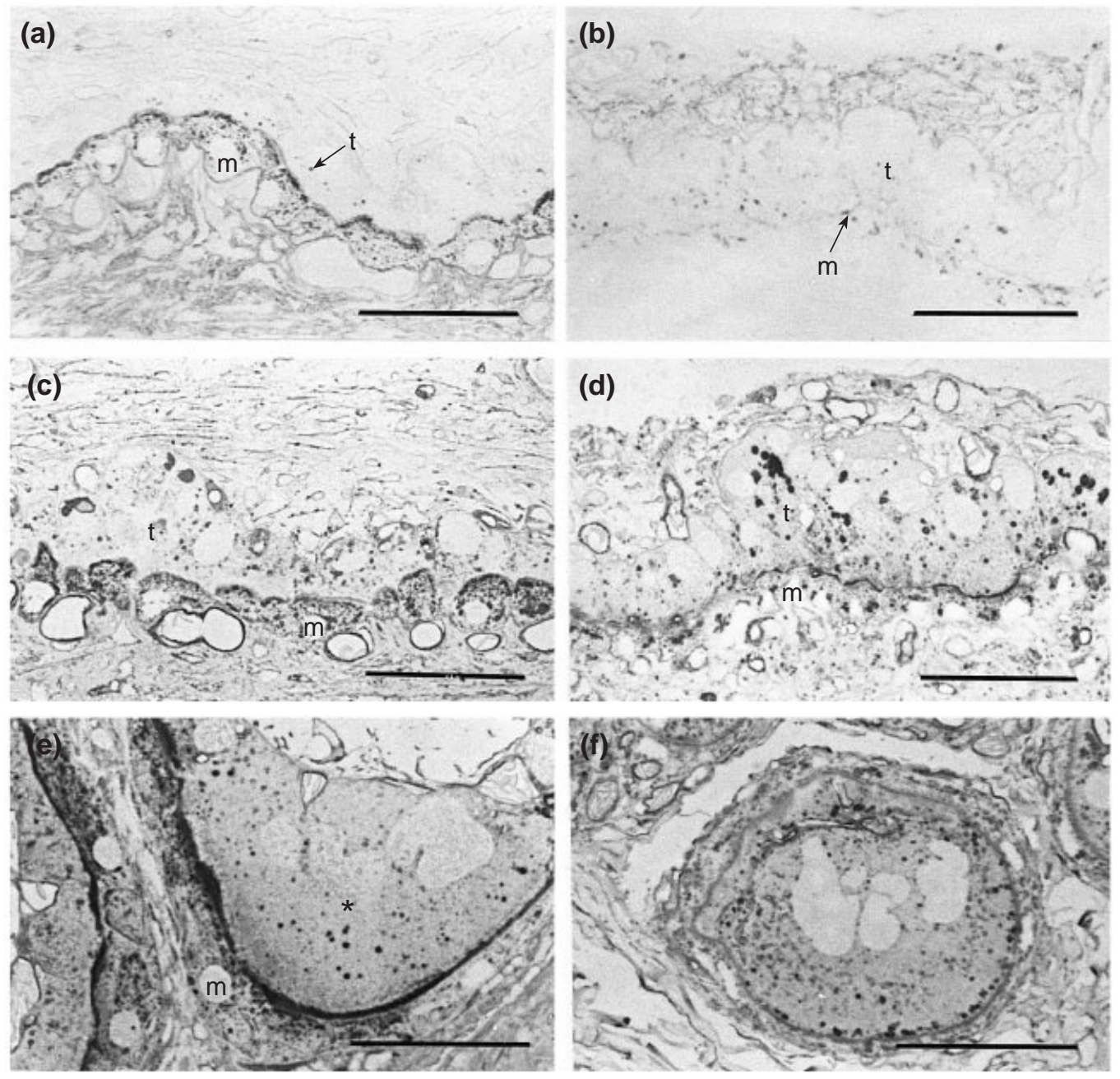

Fig. 5. (a,b) Erythrina cristagalli agglutinin (ECA). (a) At day 90 of gestation in camel, there is moderate binding to the maternal epithelium $(\mathrm{m})$ but only very occasional granules that stain in the trophoblast (t, arrow). (b) At day 45 of gestation in alpaca, neither the maternal epithelium nor the trophoblast shows much staining. (c,d) Lycopersicon esculentum (LEA). (c) At day 90 of gestation in camel, the maternal epithelium stains quite strongly and a few pleomorphic granules can be seen in the trophoblast. (d) At day 45 of gestation in alpaca, there is binding to the maternal epithelium and numerous weakly stained granules in the trophoblast, together with some intensely stained pleomorphic inclusions. (e,f) Solarum tuberosum agglutinin (STA). (e) A giant cell (*) in camel at day 170 of gestation shows more binding near the microvillous border and the maternal epithelium is stained more strongly. (f) A giant cell in alpaca at day 347 of gestation clearly shows the bizarre profiles of the nuclei. Scale bar represents $50 \mu \mathrm{m}$.

staining in the tissues. Neuraminidase treatment of sections before application of the sialic acid-binding lectins (MAA, SNA and LFA) also reduced their ability to bind.

\section{Discussion}

These findings show that, despite their common ancestry and identical diploid chromosome number $(2 n=74)$, there are several differences in the glycosylation of the fetomaternal interfaces of camels and alpacas. The most striking qualitative differences within the trophoblast are in the occurrence of bi/tri-antennary bisected $\mathrm{N}$-glycan
(e-PHA), fucosylated structures bound by DBA (GalNAc $\alpha 1,3($ Fuc $\alpha 1,2)$ Gal $\beta 1,3 / 4 G l c N A c \beta 1-), \quad \beta$-galactose (AHA) and $\alpha 2,3$-linked sialic acid (MAA). In the maternal uterine epithelium, differences are found in bisected bi/triantennary $\mathrm{N}$-glycan (e-PHA) and $\beta$-galactosyl residues (AHA). Several other minor quantitative interspecies differences were also evident. Fucosyl residues are very variable, even between closely related species (Jones et al., 2000). They are also important in cyclic changes of the endometrium in both humans and baboons (Aplin et al., 1997; Jones et al., 1998), where they may be under steroidal control based on altered binding by DBA. Fucosyl residues 
are added by fucosyl transferases. The FUT-1 gene (H-type $\alpha(1-2)$ fucosyl transferase) is hormonally modulated in mouse endometrium (Sidhu and Kimber, 1999), whereas the fucosylated H-type-I antigen has been implicated in rodent blastocyst-endometrial interactions (Kimber et al., 1995; Sidhu and Kimber, 1999). Similar mechanisms may also operate in other species. There is less sialylation in camels than in alpacas, and treatment with neuraminidase (data not shown) has little effect on the lectin binding to uterine epithelium or trophoblast in either species, confirming the scarcity of sialyl termini there. Tri/tetra-antennary bisected complex $\mathrm{N}$-glycan, shown by I-PHA staining, is also sparse in both species, whereas $\mathrm{N}$-acetyl lactosamine (DSA, WGA), $\mathrm{N}$-acetyl galactosamine (SBA, WFA) and $\mathrm{N}$-acetyl glucosamine oligomers (STA, LEA) are generally abundant.

The results of the present study indicate that there are more differences in the glycans found in the trophoblast than in the uterine epithelium, a feature that was also noted in our previous study comparing camels and horses with horses and donkeys (Jones et al., 2000). These results indicate that uterine tissues are more conserved than trophoblast with respect to glycosylation. Murphy (2000) noted that similar basolateral and apical plasma membrane alterations occur in the uterine epithelium of many species during pregnancy, despite variation in the type of placenta that is formed ultimately. There are also differences in the general structure of the two placentae: alpacas have more complex branching of the placental villi than do camels, and also have many more giant cells, although these were not described in the ultrastructural study of alpaca placenta by Steven et al. (1980). The giant cells increase in number and size during gestation and show polyploidy (L. Oliveira, personal observation); polyploidy is also observed in the giant cells of camels (Gorokhovskii et al., 1975). However, it has yet to be determined whether the nuclear profiles that are observed in camel giant cells are individual structures or part of one, or a few, large tortuous structures, as suggested by van Lennep (1961).

The similarity in lectin binding in the giant cells and uninuclear trophoblast of camels was reflected in their similar ultrastructure, as described by Skidmore et al. (1996); no obvious secretory granules were seen in their study, although lysosomes were described, which may account for some of the granular binding observed in the present study. Smooth endoplasmic reticulum was observed, which may relate to the steroid biosynthesis reported in camels (Ozturk et al., 1999), and also in rat and ruminant giant cells (Hoffman and Wooding, 1993). Much of the lectin staining is localized to very fine granular areas in the cell, which may be a reflection of glycosylation associated with subcellular organelles such as cisternae of endoplasmic reticulum, mitochondria, small electron-lucent vesicles and Golgi-associated structures, which are beyond the resolution of the light microscope and were observed at the ultrastructural level in the present study.

There have been many attempts to produce hybrids between unrelated species; other than the camel-Ilama cross there have also been attempts to cross laboratory and wild mice species (Rossant et al., 1982,1983), mice and bank voles (Mystkowska, 1975), and sheep and goats (Fehilly et al., 1984; Meinecke-Tillmann and Meinecke, 1984). In most cases, the embryos do not survive to term. Rossant et al. (1983) contended that the trophoblast was the critical factor in embryo survival as, in the mouse system, the donor inner cell mass could survive indefinitely if injected into maternal host blastocysts. This was also true in the sheep-goat cross, as mixing donor with maternal host blastocysts, or surrounding them with a host zona pellucida, so that the chorionic epithelium of the placenta developed from cells of the maternal host, resulted in the birth of sheep-goat hybrids (Fehilly et al., 1984; Meinecke-Tillmann and Meinecke, 1984). This finding implies that the surface characteristics of the trophoblast are of significance in establishing and maintaining a viable pregnancy, whether due to an immune response or other factors that contribute to the formation of a stable interface or intercellular adhesion, which in camels is a prolonged and complex process (Abd-Elnaeim et al., 1999). These factors must be appropriately 'matched' to the maternal tissues and appear to operate not just at the time of implantation but throughout the period of gestation, as some embryonic hybrids between camels and Ilamas were resorbed between day 25 and day 40 of gestation, whereas others survived up to days 260, 291 and 302 (Skidmore et al., 1999). Two other hybrids were stillborn at day 365 and one live hybrid was born prematurely at day 328 of gestation. Problems in maintenance of pregnancy were found in both directions (female camel $\times$ male alpaca and male camel $\times$ female alpaca) of cross.

This failure to maintain pregnancy is similar to observations of extraspecific donkey-in-horse pregnancy (the transfer of donkey embryos to horse mares), in which there is minimal or no microvillous attachment between fetal and maternal epithelial surfaces (Allen, 1982; Allen et al., 1987), and the endometrium does not undergo the architectural modifications that would normally provide crypts to accommodate the placental villi. Instead of the normal microvillous interdigitation, the trophoblast simply rests on the surface of the uterine epithelium, as if, according to the author (Allen, 1982) '... each epithelial surface was trying to repel rather than unite with the other...'. Trophoblast cells also produced excess secretions that formed a barrier between the two cell layers. An immunological response also developed, apparently directed against the trophoblast, and about $70 \%$ of these pregnancies were aborted (Allen et al., 1987; Allen and Short, 1997). These occurrences indicate that there may be an abnormality in the intercellular responses between maternal uterine epithelium and trophoblast, which may implicate glycan-glycan interactions, as these structures are so abundant at the two apposing cell surfaces. Oligosaccharides are capable of possessing an enormous coding capacity that can mediate cell adhesion (Solís et al., 2001). Whyte and Allen (1985) and Jones et al. (2000) have suggested that any aberration of this recognition system may cause a failure in blastocyst attachment at implantation. There are many factors that influence such 
intercellular adhesions and steroid-modulated events are of prime importance in implantation (Carson et al., 1990; Aplin, 1997), especially in relation to glycoproteins and their glycosylation (Schlafke and Enders, 1975; Cross et al., 1994; Wegner and Carson, 1994; Bowen et al., 1996; Aplin, 1997; Aplin et al., 1997; Jones et al., 1998; Johnson et al., 2000). The failure of such interactions may contribute to the difficulty in establishing interspecies hybrids, both between the camel and llama, and among equids.

The authors would like to express their grateful thanks to Karl Klisch (Centre of Anatomy, Hannover Medical School, Germany) for his kind provision of the resin-embedded block of alpaca fetal-maternal interface from day 150 of gestation, and to the Wellcome Trust for the award of a travel grant to C. J. P. Jones.

\section{References}

Abd-Elnaeim MM, Pfarrer C, Saber AS, Abou-Elmagd A, Jones CJP and Leiser $\mathbf{R}$ (1999) Feto-maternal attachment and anchorage in the early diffuse epitheliochorial placenta of the camel (Camelus dromedarius): light, transmission-, and scanning electron microscopical study Cells, Tissues, Organs 164 141-154

Allen AK and Neuberger A (1973) The purification and properties of the lectin from potato tubers, a hydroxyproline-containing glycoprotein Biochemical Journal 135 307-314

Allen WR (1982) Immunological aspects of the endometrial cup reaction and the effect of xenogeneic pregnancy in horses and donkeys Journal of Reproduction and Fertility Supplement 31 57-94

Allen WR and Short RV (1997) Interspecific and extraspecific pregnancies in equids: anything goes Journal of Heredity 88 384-392

Allen WR, Kydd JH, Boyle MS and Antczak DF (1987) Extraspecific donkeyin-horse pregnancy as a model of early fetal death Journal of Reproduction and Fertility Supplement 35 197-209

Aplin JD (1997) Adhesion molecules in implantation Reviews of Reproduction 2 84-93

Aplin JD, Jones CJP, McGinlay PB, Croxatto HB and Fazleabas AT (1997) Progesterone regulates glycosylation in endometrium Biochemical Society Transactions 25 1184-1187

Baker DA, Sugii S, Kabat EA, Ratcliffe RM, Hermentin P and Lemieux RU (1983) Immunochemical studies on the combining sites of Forssman hapten reactive hemagglutinins from Dolichos biflorus, Helix pomatia and Wisteria floribunda. Biochemistry 22 2741-2750

Baldus SE, Thiele J, Park Y-O, Hanisch F-G, Bara J and Fischer R (1996) Characterization of the binding specificity of Anguilla anguilla agglutinin (AAA) in comparison to Ulex europaeus agglutinin I (UEA-I) Glycoconjugate Journal 13 585-590

Bhattacharyya L, Haraldsson M and Brewer CF (1988) Precipitation of galactose-specific lectins by complex-type oligosaccharides and glycopeptides: studies with lectins from Ricinus communis (Agglutinin I), Erythrina indica, Erythrina arborescens, Abrus precatorius (Agglutinin), and Glycine max (Soybean) Biochemistry 27 1034-1041

Bowen JA, Bazer FW and Burghardt RC (1996) Spatial and temporal analyses of integrin and Muc-1 expression in porcine uterus epithelium and trophectoderm in vivo. Biology of Reproduction 55 1098-1106

Carson DD, Wilson O and Dutt A (1990) Glycoconjugate expression and interactions at the cell surface of mouse uterine epithelial cells and periimplantation embryos Trophoblast Research 4 211-241

Cross JC, Werb Z and Fisher SJ (1994) Implantation and the placenta: key pieces of the development puzzle Science 266 1508-1518

Crowley JF, Goldstein IJ, Arnarp J and Lönngren J (1984) Carbohydrate binding studies on the lectin from Datura stramonium seeds Archives of Biochemistry and Biophysics 231 524-533

Cummings RD and Kornfeld S (1982) Characterization of the structural determinants required for the high affinity interaction of asparagine-linked oligosaccharides with immobilized Phaseolus vulgaris leukoagglutinating and erythroagglutinating lectins Journal of Biological Chemistry 257 11230-11234

De Boeck H, Loontiens FG, Lis H and Sharon N (1984) Binding of simple carbohydrates and some $\mathrm{N}$-acetyllactosamine-containing oligosaccharides to Erythrina cristagalli agglutinin as followed with a fluorescent indicator ligand Archives of Biochemistry and Biophysics 234 297-304

Debray H, Decout D, Strecker G, Spik G and Montreuil J (1981) Specificity of twelve lectins towards oligosaccharides and glycopeptides related to $\mathrm{N}$-glycosylproteins European Journal of Biochemistry 17 41-55

Elwishy AB, Hemeida NA, Omar MA, Mobarak AM and El Sayed MAI (1981) Functional changes in the pregnant camel with special reference to foetal growth British Veterinary Journal 137 527-537

Etzler ME and Kabat EA (1970) Purification and characterization of a lectin (plant hemagglutinin) with blood group A specificity from Dolichos biflorus. Biochemistry 9 869-877

Fehilly CB, Willadsen SM and Tucker EM (1984) Interspecific chimaerism between sheep and goat Nature 307 634-636

Gallagher JT, Morris A and Dexter TM (1985) Identification of two binding sites for wheat-germ agglutinin on polylactosamine-type oligosaccharides Biochemical Journal 231 115-122

Gee H (1999) Hybrid camel bridges 11 million years Nature Science Update May 6, 1999 (http://www.nature.com/nsu/990506/9905067.html)

Gorokhovskii NL, Shmidt GA, Shabaeva VG and Baptidanova IP (1975) Giant cells in the placenta of the bactrian camel in the fetal period of development Arkhiv Anatomii Gistologii i Embriologii 69 41-46

Gray AP (1972) Mammalian Hybrids Technical Communication No. 10 (Revised) of the Commonwealth Bureau of Animal Breeding and Genetics, Edinburgh

Green ED and Baenziger JU (1987) Oligosaccharide specificities of Phaseolus vulgaris leukoagglutinating and erythroagglutinating phytohemagglutinins. Interactions with $\mathrm{N}$-glycanase-released oligosaccharides Journal of Biological Chemistry 26212 018-12 029

Hammerström S, Murphy LA, Goldstein IJ and Etzler ME (1977) Carbohydrate binding specificity of four $\mathrm{N}$-acetyl-D-galactosamine"specific" lectins: Helix pomatia A hemagglutinin, soybean agglutinin, lima bean lectin and Dolichos biflorus lectin Biochemistry $\mathbf{1 6}$ 2750-2755

Hammarström S, Hammarström ML, Sunblad G, Arnarp J and Lönngren J (1982) Mitogenic leukoagglutinin from Phaseolus vulgaris binds to a pentasaccharide unit in $\mathrm{N}$-acetyllactosamine-type glycoprotein glycans Proceedings National Academy of Sciences USA 79 1611-1615

Hindsgaul O, Khare DP, Bachm $\mathbf{M}$ and Lemieux RU (1985) Molecular recognition III. The binding of the H-type 2 human blood group determinant by the lectin of Ulex europaeus. Canadian Journal of Chemistry 63 2653-2658

Hoffman LH and Wooding FBP (1993) Giant and binucleate trophoblast cells of mammals Journal of Experimental Zoology 266 559-577

Iglesias JL, Lis H and Sharon N (1982) Purification and properties of a Dgalactose/ $\mathrm{N}$-acetyl-D-galactosamine-specific lectin from Erythrina cristagalli. European Journal of Biochemistry 123 247-252

Johnson GA, Spencer TE, Burghardt RC, Taylor KM, Gray CA and Bazer FW (2000) Progesterone modulation of osteopontin gene expression in the ovine uterus Biology of Reproduction 62 1315-1321

Jones CJP, Mosley SM, Jeffrey IJM and Stoddart RW (1987) Elimination of the non-specific binding of avidin to tissue sections Histochemical Journal 19 264-268

Jones CJP, Jauniaux E and Stoddart RW (1995) Glycans of the early human yolk sac Histochemical Journal 27 210-221

Jones CJP, Fazleabas AT, McGinlay PB and Aplin JD (1998) Cyclic modulation of epithelial glycosylation in human and baboon (Papio anubis) endometrium demonstrated by the binding of the agglutinin from Dolichos biflorus (DBA) Biology of Reproduction 58 20-27

Jones CJP, Wooding FBP, Abd-Elnaeim MM, Leiser R, Dantzer V and Stoddart RW (2000) Glycosylation in the near-term epitheliochorial placenta of the horse, donkey and camel: a comparative study of interbreeding and non-interbreeding species Journal of Reproduction and Fertility 118 397-405 
Kimber SJ, Illingworth IM and Glasser SR (1995) Expression of carbohydrate antigens in the rat uterus during early pregnancy and after ovariectomy and steroid replacement Journal of Reproduction and Fertility 103 75-87

Knibbs RN, Goldstein IJ, Ratcliffe RM and Shibuya N (1991) Characterization of the carbohydrate binding specificity of the leukoagglutinating lectin from Maackia amurensis. Journal of Biological Chemistry 266 83-88

Knibbs RN, Osborne SE, Glick GD and Goldstein IJ (1993) Binding determinants of the sialic acid-specific lectin from the slug Limax flavus. Journal of Biological Chemistry $26818524-18531$

Lotan R and Sharon N (1978) Peanut (Arachis hypogaea) agglutinin Methods in Enzymology 50 361-367

Maddox PH and Jenkins D (1987) 3'Aminopropyltriethoxysilane (APES): a new advance in section adhesion Journal of Clinical Pathology $\mathbf{4 0}$ 1256-1260

Meinecke-Tillmann S and Meinecke B (1984) Experimental chimaeras removal of reproductive barrier between sheep and goats Nature 307 637-638

Miller RL, Collawn JF and Fish WW (1982) Purification and macromolecular properties of a sialic acid-specific lectin from the slug Limax flavus. Journal of Biological Chemistry 257 7574-7580

Murphy CR (2000) The plasma membrane transformation of uterine epithelial cells during pregnancy Journal of Reproduction and Fertility Supplement 55 23-28

Mystkowska ET (1975) Development of mouse-bank vole interspecific chimaeric embryos Journal of Experimental Morphology 33 731-744

Nachbar MS, Oppenheim JD and Thomas JO (1980) Lectins in the U.S. Diet. Isolation and characterization of a lectin from the tomato (Lycopersicon esculentum). Journal of Biological Chemistry 255 2056-2061

Ozturk M, Skidmore J, Allen WR and Wooding FBP (1999) Developmental changes in localization of steroid synthesis in the camel placenta Journal of Physiology 517P 32P

Pereira MEA and Kabat EA (1974) Specificity of purified hemagglutinin (lectin) from Lotus tetragonolobus. Biochemistry 13 3184-3192

Pereira MEA, Kabat EA and Sharon N (1974) Immunochemical studies on the specificity of Soybean agglutinin Carbohydrate Research 37 89-102

Roemer I, Grützner F, Winking H, Haaf T, Orth A, Skidmore L, Antczak D and Fundele R (1999) Global methylation in eutherian hybrids Nature 401 131-132

Rossant J, Croy BA, Chapman VM, Siracusa L and Clark DA (1982) Interspecific chimeras in mammals: a new experimental system Journal of Animal Science 55 1241-1248

Rossant J, Croy BA, Clark DA and Chapman VM (1983) Interspecific hybrids and chimeras in mice Journal of Experimental Zoology $\mathbf{2 2 8}$ 223-233

Sarkar M, Wu AM and Kabat EA (1981) Immunochemical studies on the carbohydrate specificity of Maclura pomifera lectin Archives of Biochemistry and Biophysics 209 204-218

Schlafke S and Enders AC (1975) Cellular basis of interaction between trophoblast and uterus at implantation Biology of Reproduction 12 41-65

Shibuya N, Goldstein IJ, Broekaert WF, Nsimba-Lubaki M, Peeters B and Peumans WJ (1987) The elderberry (Sambucus nigra L.) bark lectin recognizes the $\operatorname{Neu} 5 \mathrm{Ac}(\alpha 2,6) \mathrm{Gal} / \mathrm{GalNAc}$ sequence Journal of Biological Chemistry 262 1596-1601

Sidhu SS and Kimber SJ (1999) Hormonal control of H-type $\alpha(1-$ 2)fucosyltransferase messenger ribonucleic acid in the mouse uterus Biology of Reproduction 60 147-157
Skidmore JA, Wooding FBP and Allen WR (1996) Implantation and early placentation in the one-humped camel (Camelus dromedarius). Placenta 17 253-262

Skidmore JA, Billah M, Binns M, Short RV and Allen WR (1999) Hybridizing old and new world camelids: Camelus dromedarius $\times$ Lama guanicoe. Proceedings of the Royal Society, London, Series B 266 649-656

Solís D, Jiménez-Barbero J, Kaltner H, Romero A, Siebert H-C, von der Lieth C-W and Gabius H-J (2001) Towards defining the role of glycans as hardware in information storage and transfer: basic principles, experimental approaches and recent progress Cells, Tissues, Organs 168 5-23

Stanley HF, Kadwell M and Wheeler JC (1994) Molecular evolution of the family Camelidae: a mitochondrial DNA study Proceedings of the Royal Society, London, Series B 256 1-6

Steven DH, Burton GJ, Sumar J and Nathanielsz PW (1980) Ultrastructura observations on the placenta of the alpaca (Lama pacos). Placenta 1 21-32

Sueyoshi S, Tsuji T and Osawa T (1988) Carbohydrate-binding specificities of five lectins that bind to O-glycosyl-linked carbohydrate chains. Quantitative analysis by frontal-affinity chromatography Carbohydrate Research 178 213-224

Sugii S and Kabat EA (1980) Immunochemical specificity of the combining site of Wisteria floribunda hemagglutinin Biochemistry 19 1192-1199

Taylor P (2000) Camel/lama cross The Alpaca Registry Journal 5 Spring 2000 (http://www.alpacaregistry.net/journal/spr2000.04.html)

Torres BV, McCrumb DK and Smith DF (1988) Glycolipid-lectin interactions: reactivity of lectins from Helix pomatia, Wisteria floribunda and Dolichos biflorus with glycolipids containing $\mathrm{N}$-acetylgalactosamine Archives of Biochemistry and Biophysics 262 1-11

Trowbridge IS (1974) Isolation and chemical characterization of a mitogenic lectin from Pisum sativum. Journal of Biological Chemistry 249 6004-6012

Van Lennep EW (1961) The histology of the placenta of the one-humped camel (Camelus dromedarius L.) during the first half of pregnancy Acta Morphologica Neerlando-Scandinavica 4 180-193

Wang W-C and Cummings RD (1988) The immobilized leukoagglutinin from the seeds of Maackia amurensis binds with high affinity to complex-type Asn-linked oligosacharides containing terminal sialic acid-linked $\alpha 2,3$ to penultimate galactose residues Journal of Biological Chemistry 263 4576-4585

Wegner CC and Carson DD (1994) Cell adhesion processes in implantation Oxford Reviews of Reproductive Biology 16 87-137

Whyte A and Allen WR (1985) Equine endometrium at pre-implantation stages of pregnancy has specific glycosylated regions. Placenta 6 537-542

Wright W (1999) Camel centre tries to produce three more camas Gulf News 25 February 1999 (http://www.datadubai.com/cama1.htm)

Yamashita K, Hitoi A and Kobata A (1983) Structural determinants of Phaseolus vulgaris erythroagglutinating lectin for oligosaccharides Journal of Biological Chemistry $25814753-14755$

Yamashita K, Totani K, Ohkura T, Takasaki S, Goldstein IJ and Kobata A (1987) Carbohydrate binding properties of complex-type oligosaccharides on immobilized Datura stramonium lectin Journal of Biological Chemistry 262 1602-1607

Received 26 July 2001.

First decision 10 September 2001.

Accepted 8 October 2001. 